\title{
Step-Path method - impact of defect occurrence, cut-off and length on shear strength in rock slopes
}

NRP Baczynski Prime Geotechnics Pty Ltd, Australia

\begin{abstract}
Examples of statistical models for geological defect attributes are presented. Whilst data collection errors can occur for all attributes, the factors specifically influencing defect length measurements are examined in more detail. Mapped lengths may underestimate actual lengths by 60 to $80 \%$. Hoek-Brown and Step-Path methods are used to estimate shear strength of failure paths through rock slopes. Both methods are compared. For the inputs considered, Step-Path method may yield shear strength results that are up to 40\% lower than Hoek-Brown results. Inputs influencing Step-Path results are examined. Implications of Hoek-Brown and Step-Path results for pit slope design Factors of Safety are discussed.
\end{abstract}

\section{Introduction}

The Hoek-Brown rock mass shear strength model (Hoek \& Brown 1980a, 1980b) with its various enhancements and revisions, including the more recent ones for low unconfined compressive strength (UCS) strength rock masses (Carvalho et al. 2007), has now been with us for 35 years. Without doubt, the Hoek-Brown approach is a most widely used method for rock slope design.

Perhaps the earliest mention in technical literature of a Step-Path type approach for estimating rock mass shear strength dates back to Jennings (1970) who postulated its use for computing the relative contribution of intact rock bridges between ubiquitous bedding plane defects to overall stability of rock slopes.

A major boost to Step-Path approaches occurred during 1970-1980s. The late Dr Barry McMahon (1971, 1974 and 1979) developed, in FORTRAN66, the STEPSIM Monte-Carlo simulation software for computing a statistical shear strength model (Read \& Lye 1983) for input to limit equilibrium stability analysis of rock slopes at the Bougainville copper mine in Papua New Guinea (PNG). This code was subsequently applied in the early 1990s for computing statistical rock mass shear strength inputs to stability analysis of Ok Tedi Mine rock slopes.

During 1997-2000, Ok Tedi Mine undertook a major review of its pit slope design. As part of this review, the McMahon's STEPSIM software was revised and upgraded (Baczynski 2000) and the resulting STEPSIM4 code (in FORTRAN77) was used for stability analysis of the mine's slopes (Little et al. 1999). Over the last 15 years, the author has advocated and applied the STEPSIM4 code and similar Excel spreadsheet based Modified Step-Path approaches on many mine pit slopes.

For completeness of the discussion; this paper briefly overviews inputs to and outputs from the Step-Path approach, identifies rock mass situations where the Step-Path method is likely to yield more representative and invariably lower shear strength parameters than the Hoek-Brown method and presents an example of how the computed strength models differ.

The statistical length of geological defect is a key input to the Step-Path approach. Factors that impact and frustrate our ability to suitably determine this parameter are discussed. Defect length models and common errors in the estimation process are presented.

A real-case based conceptual example is presented to show likely impact of defect probability of occurrence, probability of cut-off and length on Step-Path shear strength. 


\section{Hoek-Brown method}

The Hoek-Brown method has been described in numerous technical papers since 1980 . Further elaboration is not warranted.

It suffices to note that there are four inputs to the Hoek-Brown method.

Inputs are the intact rock UCS, the Geological Strength Index (GSI) which can be determined directly from a rock mass blockiness versus geological defects condition charts or by transformation from Bieniawski (1989) Rock Mass Rating (RMR) Index, the $m_{i}$ parameter which describes the shape of the normal-shear strength curve and a disturbance factor $\mathrm{D}(0$ to 1$)$.

\section{Is Hoek-Brown method always applicable?}

Orientation of geological defects is not considered in the Hoek-Brown method.

Yet evidence on many rock slope failures is that defects had controlled at least some parts of critical failure paths through rock masses. This raises the question whether the Hoek-Brown method is always the best approach for all rock masses.

As conceptually shown in Figure 1, defects rather than rock mass are likely to control the shear strength of critical failure path along those sections that are co-aligned with mean defect set orientations.
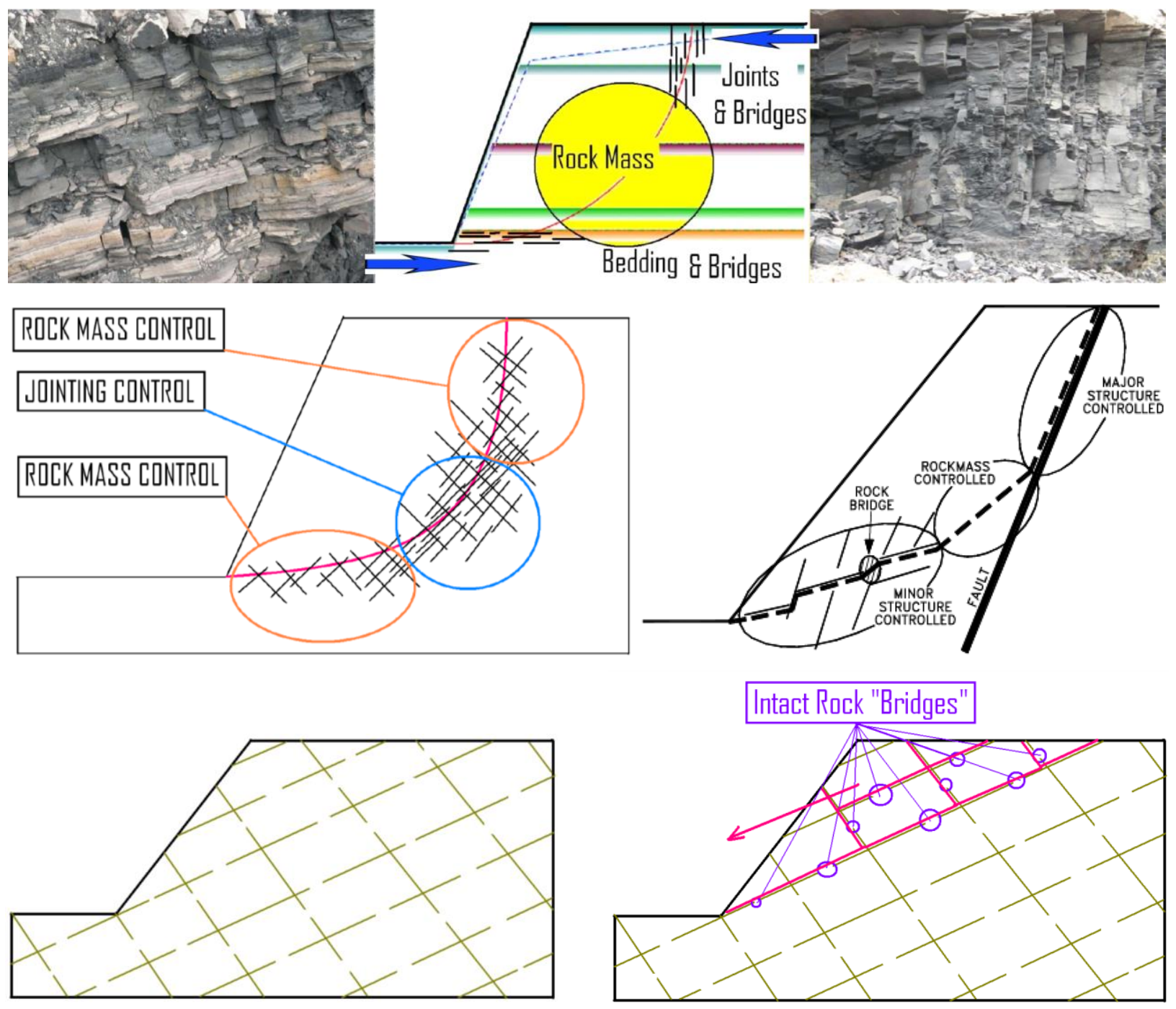

Figure 1 Examples of situations where geological defects are likely to control the shear strength of critical failure paths through jointed rock mass slopes 


\section{$4 \quad$ Step-Path method}

The original McMahon Step-Path method determined shear strength along potential failure paths through a rock mass slope by Monte-Carlo statistical generation of geological defects and bridges between defects (Baczynski 2000).

Akin to the approach used by Baczynski (1980) for large underground mine openings, the Step-Path rock mass slope is visualised as comprising a network of equal-sized blocks or cells. Figure 2 shows Step-Path basics concepts.
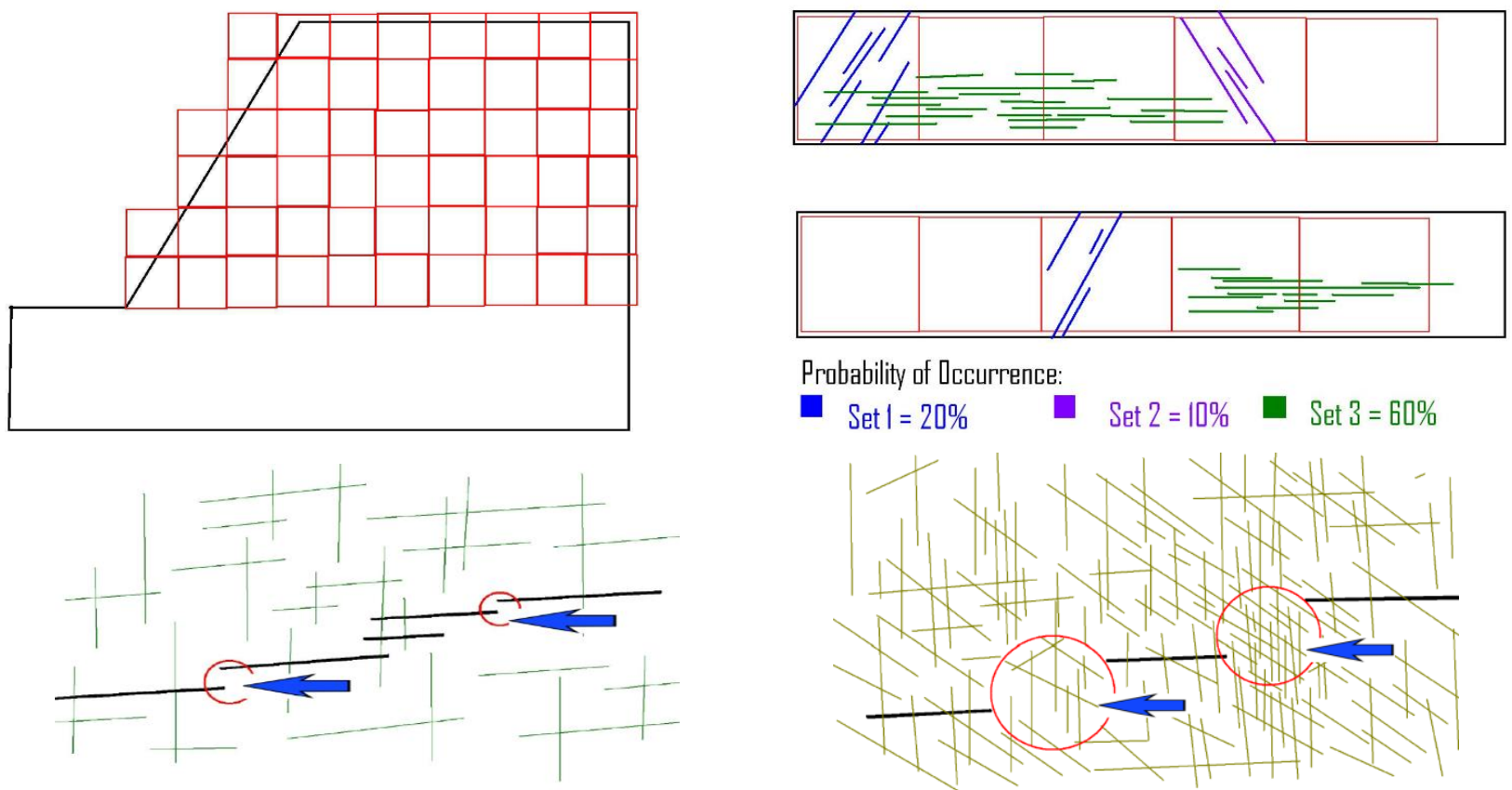

INTACT ROCK "BRIDGES”
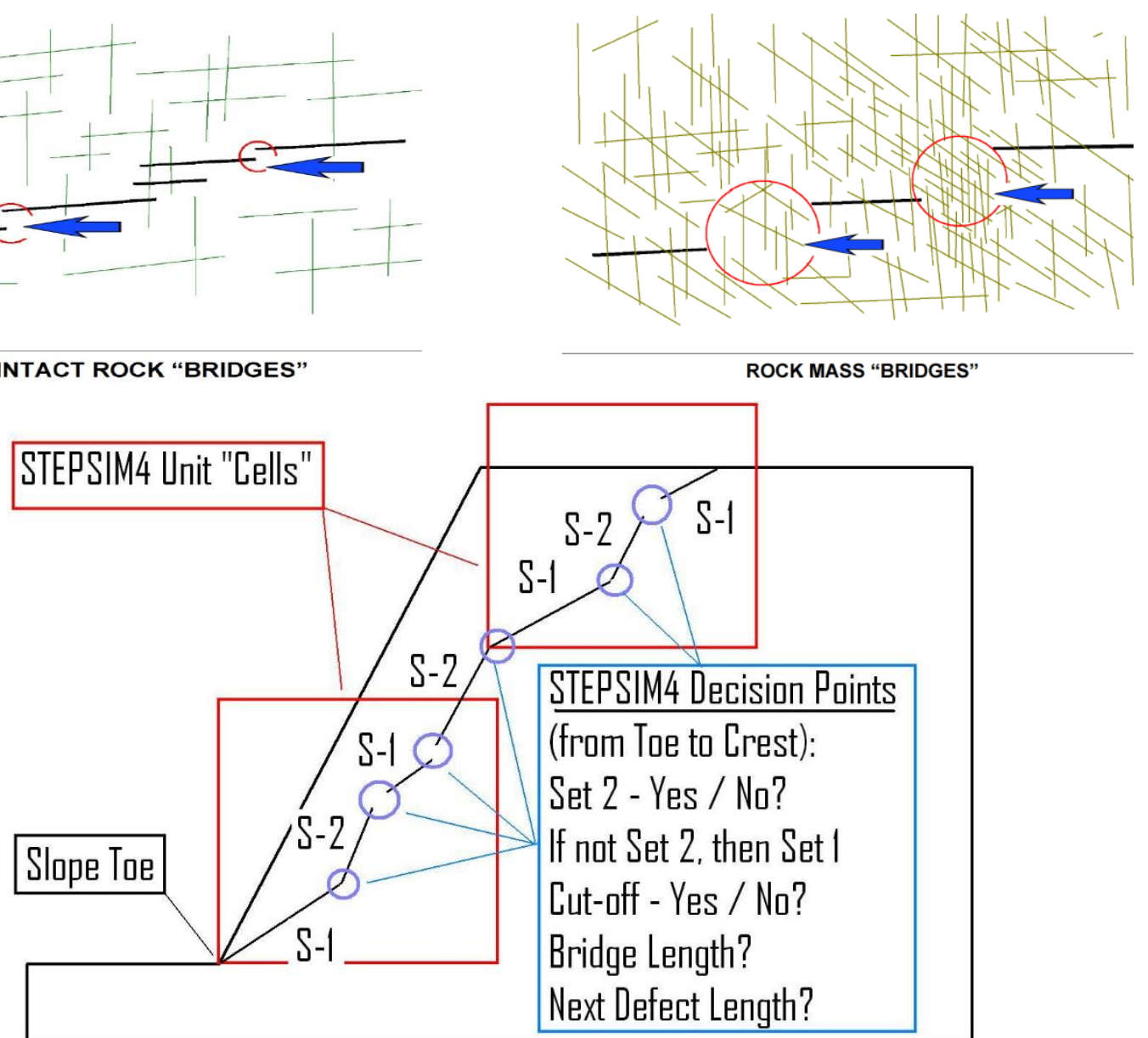

Figure 2 Several Step-Path concepts: network of blocks, probability of defect occurrence, intact rock and rock mass bridges, and the STEPSIM4 simulation process for two defect sets model

In the revised STEPSIM4 code, any block-size is user specified; although $10 \times 10 \mathrm{~m}$ blocks are often adopted. STEPSIM4 considers two user-selected, defect set orientations; but each set can be further partitioned into joints and faults with their own respective statistical attributes. 
Four basic geotechnical conditions may exist in each STEPSIM4 block.

- User-selected defect sets do not occur (i.e. general rock mass conditions exist).

- Defect set 1 occurs only.

- Defect set 2 occurs only.

- Both Defect sets 1 and 2 occur.

The STEPSIM4 Monte-Carlo simulation process requires the following statistical models for each user-selected defect set.

- Probability of defect occurrence in each STEPSIM4 rock mass block (0-100\%).

- Defect length (i.e. statistical model type - normal, lognormal; mean, -1 and +1 standard deviation).

- Defect shear strength (i.e. effective friction and cohesion for designated normal stress).

- Defect cut-off (i.e. probability that defects are truncated by other defects; 0-100\%).

- Length of intact rock/rock mass bridges between non cut-off defects (i.e. statistical model type normal, lognormal; mean, -1 and +1 standard deviation).

- Intact rock/rock mass bridge strength (i.e. effective friction and cohesion for designated normal stress).

For each user-specified normal stress condition (e.g. 0.05, 0.1, 0.5, 1, 2, 5, 10, $15 \mathrm{MPa}$ etc.), the Monte-Carlo process is continued until the user-specified target Step-Path length (e.g. 500 or 1,000 m) is fully simulated and this analysis is repeated the user-specified number of times (e.g. for 5,000 to 10,000 target Step-Paths). Results are statistically processed. Outputs comprise the normal stress dependent mean and standard deviation for effective friction angle and cohesion along the target length Step-Path.

\section{$5 \quad$ Defect length measurement}

Defect length can only be determined by mapping of slope faces or walls of underground openings.

Except for high continuity faults intersected and confidently correlated between several boreholes, defect length cannot be determined by drilling alone; although drilling does provide an estimate of the relative proportion of defects that are shorter than the minimum defect length (say 1 or $2 \mathrm{~m}$ ) that might have been adopted by the geotechnical engineer for slope face mapping purposes. The writer's comparison of drilling and mapping derived defect set spacing on several projects suggests that, in some rock masses, defects shorter than $1 \mathrm{~m}$ may account for 60 to $85 \%$ of the length population.

Figure 3 shows a case study of an evolving defect length model developed on the basis of three line traverse data types, i.e. photo lineaments, slope face mapping and orientated drill core for an intrusive rock type at the Ok Tedi Mine in PNG. 

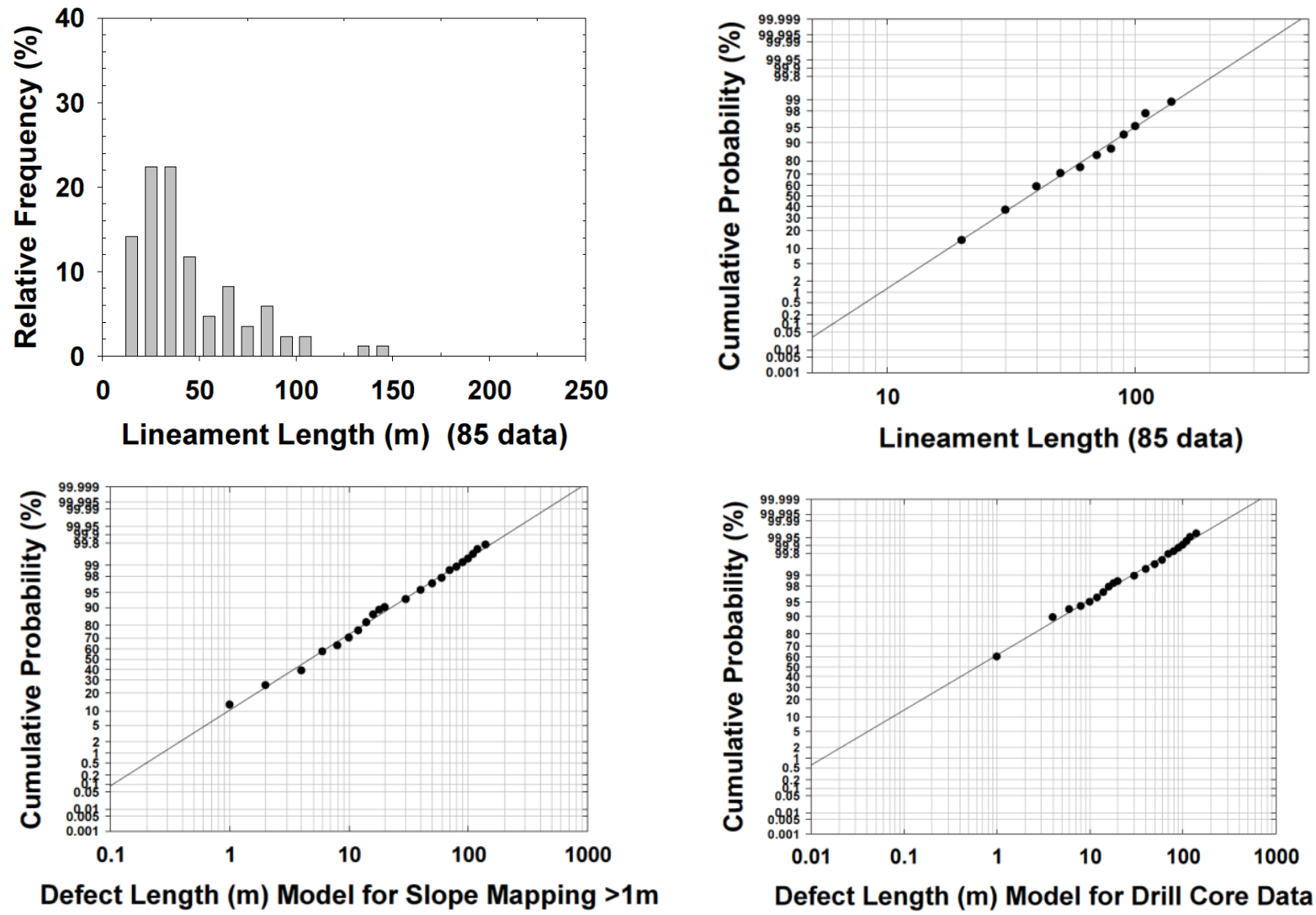

Figure 3 Evolving defect length model: lineament data only, lineament plus slope face mapping data, and final model after consideration of all data including drill cores

In the example shown in Figure 3, the median length decreases from approximately $40 \mathrm{~m}$ for lineaments, to $5 \mathrm{~m}$ for lineaments plus slope face mapping, to $0.6 \mathrm{~m}$ for all data types combined.

Three types of surface and underground mapping can be undertaken:

- Line traverse (1-dimensional).

- Area-mapping (2-dimensional).

- Volume-mapping (3-dimensional).

The first two mapping types are most commonly used by geotechnical engineers; although early 1990s discussions with Dr McMahon indicated that defect attributes for his original STEPSIM Step-Path software were obtained by volume-mapping (i.e. bench tops and faces at Bougainville).

The three mapping types yield widely different statistical length models. With increasing dimension (1 to 3 ), there is a progressively greater proportion of shorter defects to be considered. Figure 4 and Table 1 demonstrates the respective statistical length differences for a conceptual example. 

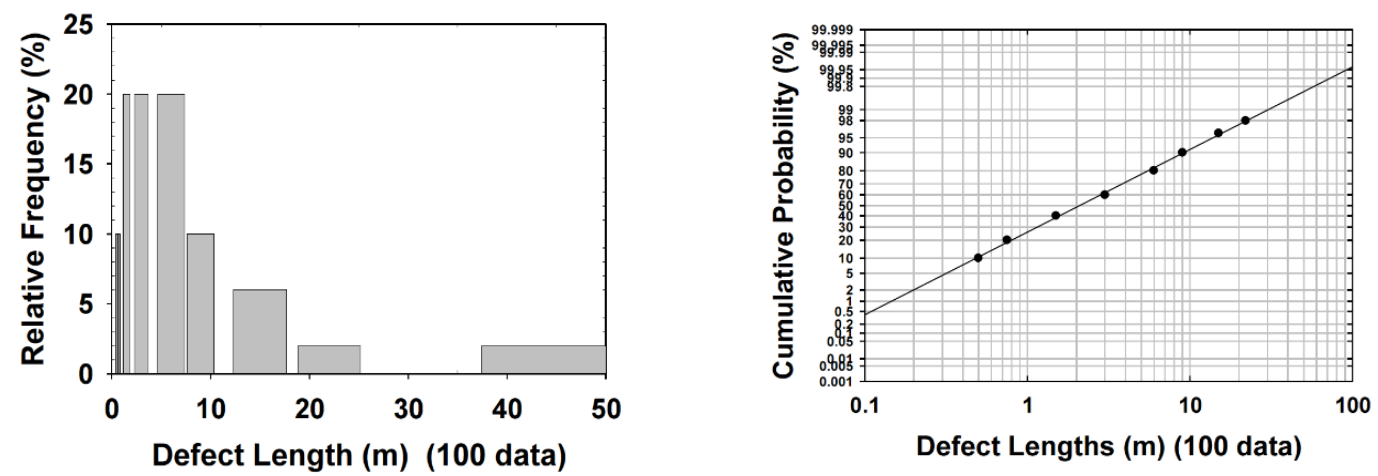

(a)
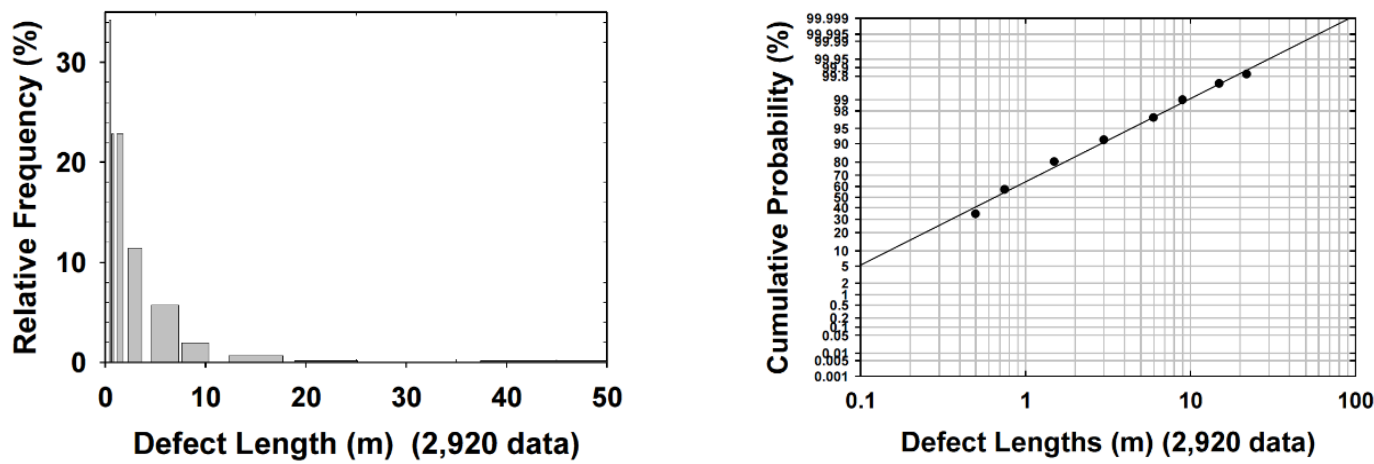

(b)
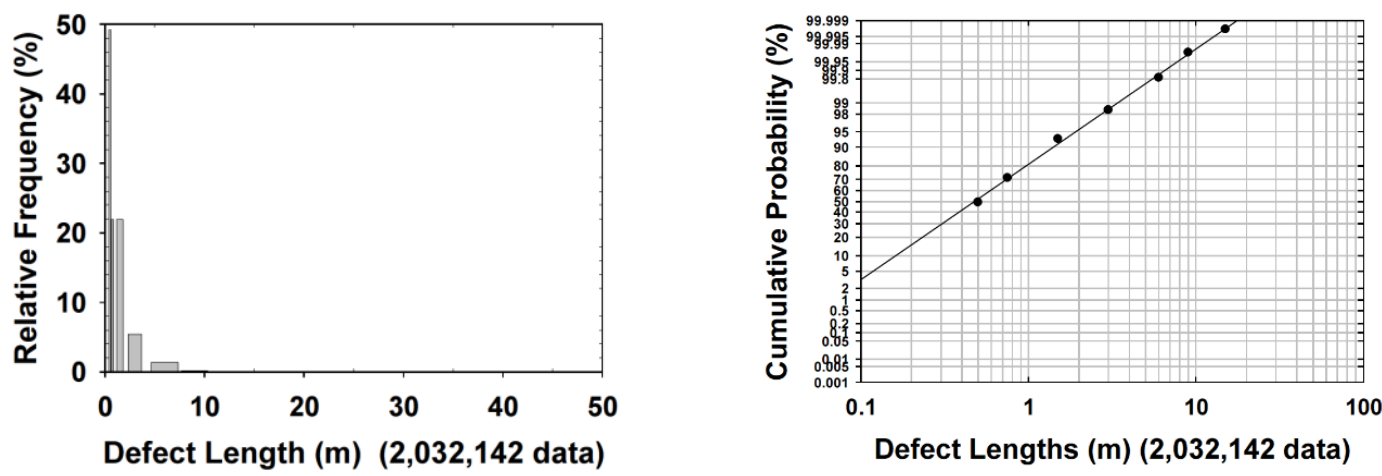

(c)

Figure 4 Impact of mapping type on defect length model: (a) 1D line-traverse mapping; (b) 2D area/window mapping; and, (c) 3D volume/block mapping

Table 1 Impact of mapping type on defect length model

\begin{tabular}{lccc}
\hline \multirow{2}{*}{$\begin{array}{l}\text { Defect length statistical parameter } \\
\text { (Lognormal base 10 distribution) }\end{array}$} & \multicolumn{3}{c}{ Mapping type and defect length $(\mathbf{m})$} \\
\cline { 2 - 4 } & 1D line-traverse & 2D area/window & 3D volume/block \\
\hline Mode & 1.00 & 0.65 & 0.25 \\
\hline Median & 2.10 & 0.65 & 0.48 \\
\hline Mean & 4.07 & 1.30 & 0.70 \\
\hline $\mathbf{- 1}$ standard deviation & 0.65 & 0.20 & 0.20 \\
\hline $\mathbf{+ 1}$ standard deviation & 6.50 & 2.10 & 0.70 \\
\hline Risk of defects $>$ 20 m length & $\pm 3 \%$ & $<0.2 \%$ & $<0.001 \%$ \\
\hline
\end{tabular}


In the example shown in Figure 4 and Table 1, the median length decreases from approximately $2.1 \mathrm{~m}$ for 1D line traverse mapping to $0.5 \mathrm{~m}$ for 3D volume/block mapping.

The mapping type requirement for Step-Path analyses is line-traverse.

\section{Defect plane shape and measured length}

Figure 5 shows conceptual examples of defect plane shapes and defect trace lengths of slope faces. Trace length depends on:

- Actual diameter/2D lateral extent of the defect plane.

- Shape of the defect plane (i.e. circular, elliptical, square, rectangular, irregular).

- Distance of the defect plane centre to slope face being mapped.

The statistical distribution of mapped lengths depends on the statistical characteristics of the actual lengths.

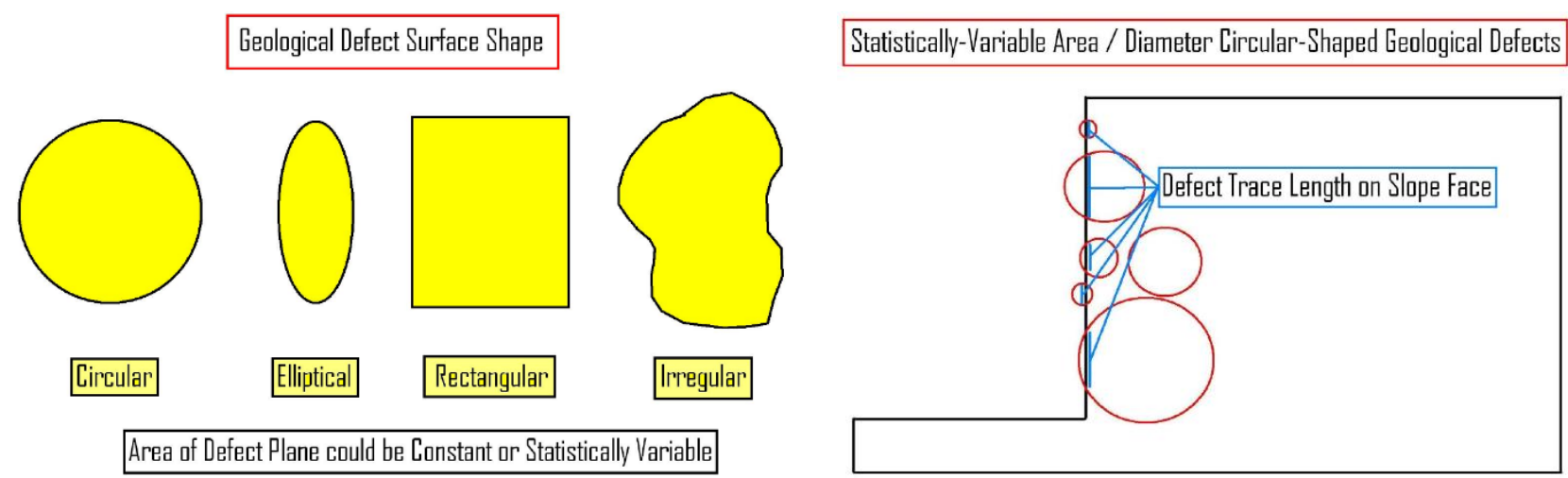

Figure 5 Defect plane shapes and actual defect diameters and apparent trace lengths on slope face

If the actual defects lengths are constant diameter, then the relative frequency of the mapped lengths will resemble a positive-skewed exponential function.

If the actual defect lengths are lognormally distributed, then the mapped lengths can also be approximated by a lognormal distribution; with statistical attributes of the mapped lengths being significantly less than those of the actual lengths (as shown in Table 2 and Figure 6).

Table 2 Actual and apparent (as mapped) statistical distributions for defect lengths

\begin{tabular}{lcc}
\hline \multirow{2}{*}{$\begin{array}{l}\text { Defect length statistical parameter } \\
\text { (Lognormal base 10 distribution) }\end{array}$} & \multicolumn{2}{c}{ Defect length (m) } \\
\cline { 2 - 3 } & Actual (as simulated) & Apparent (as mapped) \\
\hline Mode & 1.25 & 1.25 \\
\hline Median & 2.10 & 1.40 \\
\hline Mean & 4.18 & 2.40 \\
\hline -1 standard deviation & 0.65 & 0.50 \\
\hline +1 standard deviation & 6.80 & 4.00 \\
\hline
\end{tabular}

The determined mean actual and mean apparent defect lengths are used to examine the impact on Step-Path shear strengths. 

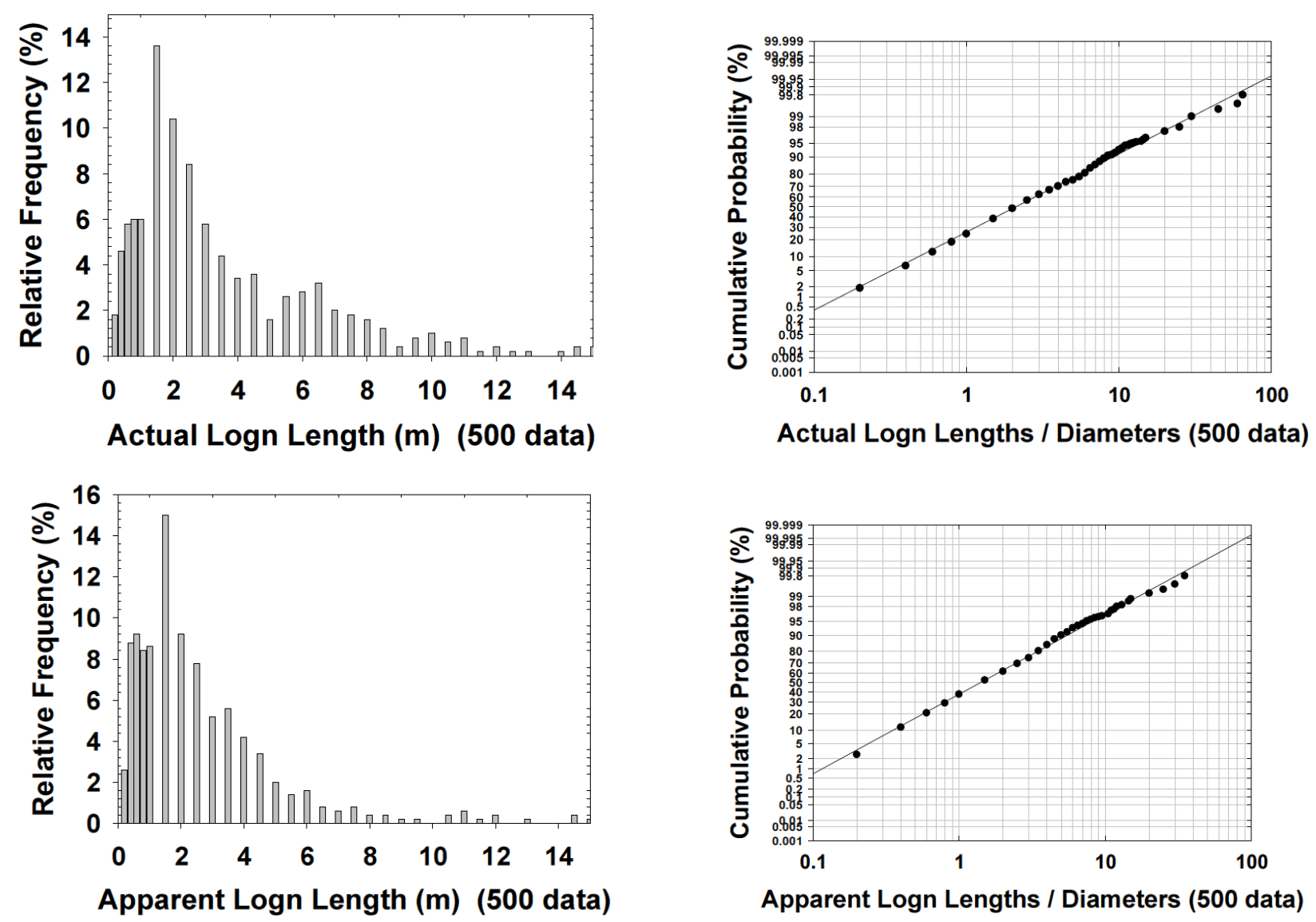

Figure 6 Actual and apparent (as mapped) statistical distributions for defect lengths

\section{Observed defect plane shapes}

Apart from his own limited observations, the writer is not aware of any other significant study to assess defect plane shapes.

Baczynski (1980) observed that defects in bedded strata at Mount Isa Mine were approximately rectangular (or elliptical) with a length ratio along bedding to normal to bedding of approximately 1 to 0.44 . As shown in Figure 7, this relationship was developed by mapping subhorizontal defects in underground openings trending along strike and normal to strike of the stratification. Other ad hoc observations in mine slopes since 2000 suggest that this ratio might even be as low as 1 to 0.25 in some sedimentary rock types. 


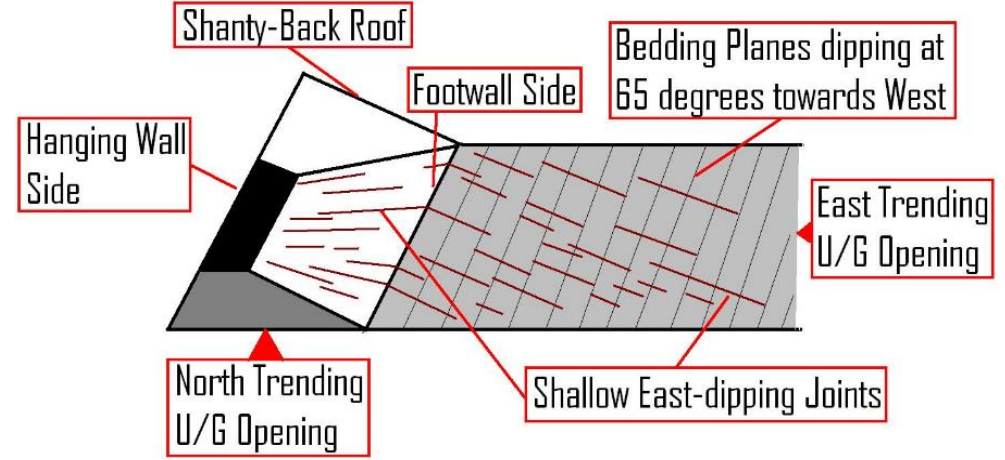

(a)

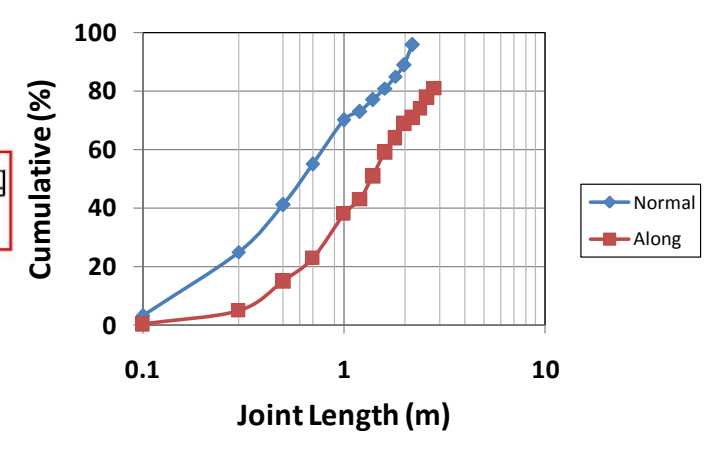

Joint Length $(m)$
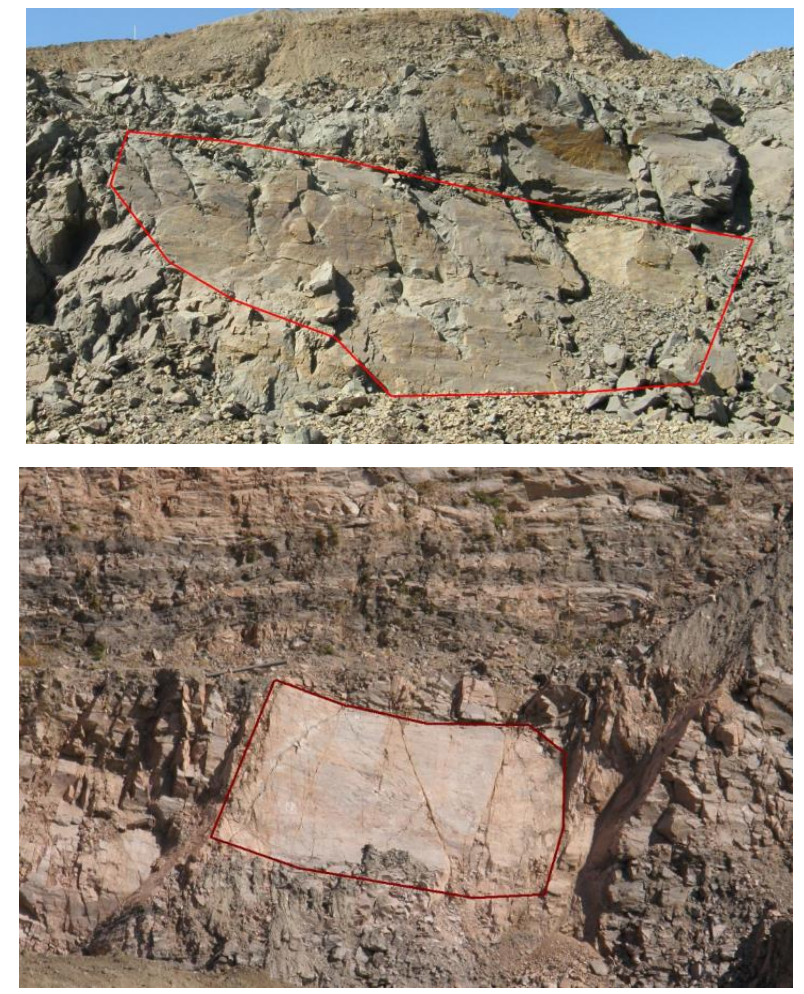
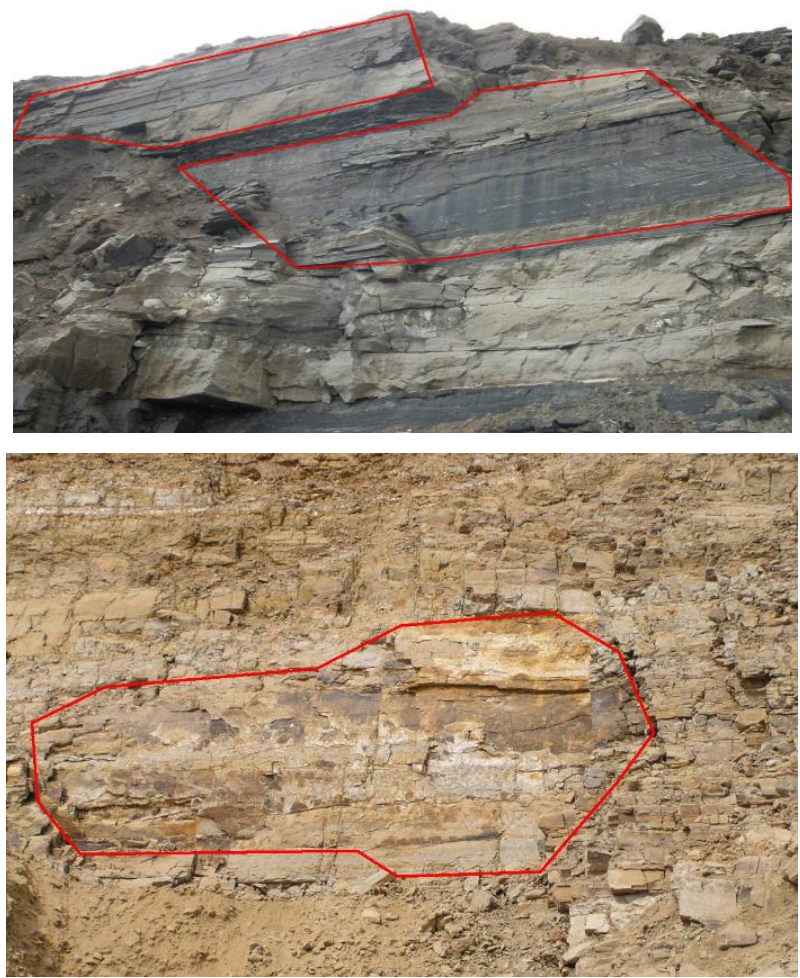

(b)

Figure 7 Stratification control on defect shapes: (a) underground mapping of defects at Mount Isa Mine, Queensland; and, (b) photographic evidence in various open pit mine slopes

\section{Defect surface roughness}

Defect surface roughness often exists at two scales of observation.

- Small-scale surface roughness (SSSR) as initially defined by Barton (1976) and observed over a defect surface trace length of $100 \mathrm{~mm}$. This parameter is rated on a scale of 1 to 10 . Barton's Joint Roughness Coefficient input to the initial version of defect shear strength equation is SSSR multiplied by two.

- Large-scale surface roughness (LSSR) or defect surface undulations; often displaying wavelengths of 0.5 to $5 \mathrm{~m}$ and amplitude of 0.05 to $0.5 \mathrm{~m}$. This parameter may be expressed as a roughness angle which is computed via Tangent (amplitude/[0.5 $\times$ wavelength]).

Based on the writer's field investigations, the SSSR is most often normally distributed (see Figure 8), whereas the LSSR angle is lognormally distributed (see Figure 9). 
New South Wales Mine: Example 2004

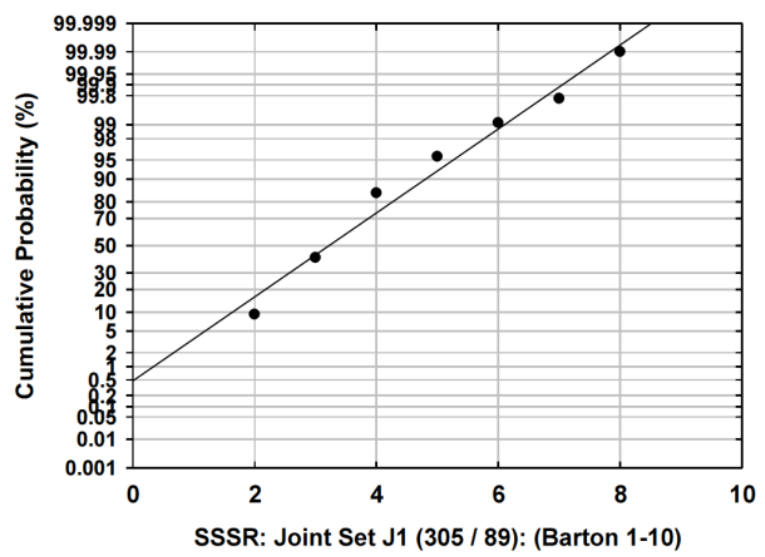

New South Wales Mine: Example 2004

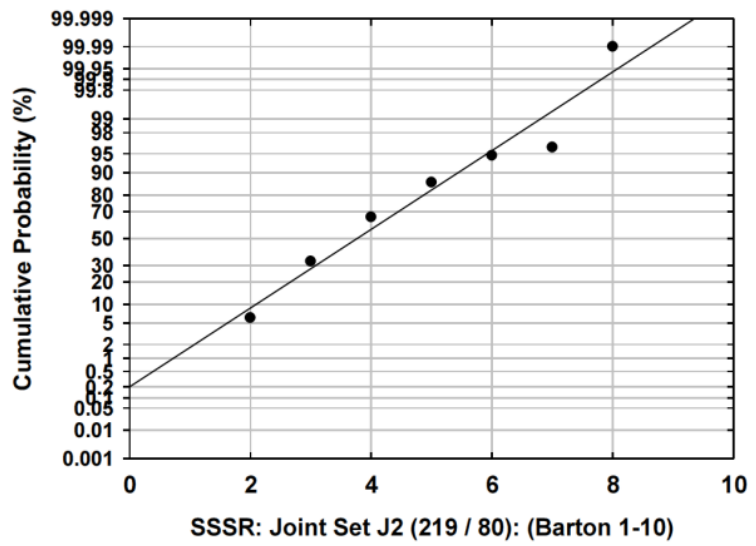

Figure 8 Examples of normally-distributed small-scale surface roughness (Barton's scale of 1 to 10)

New South Wales Mine: Example 2004

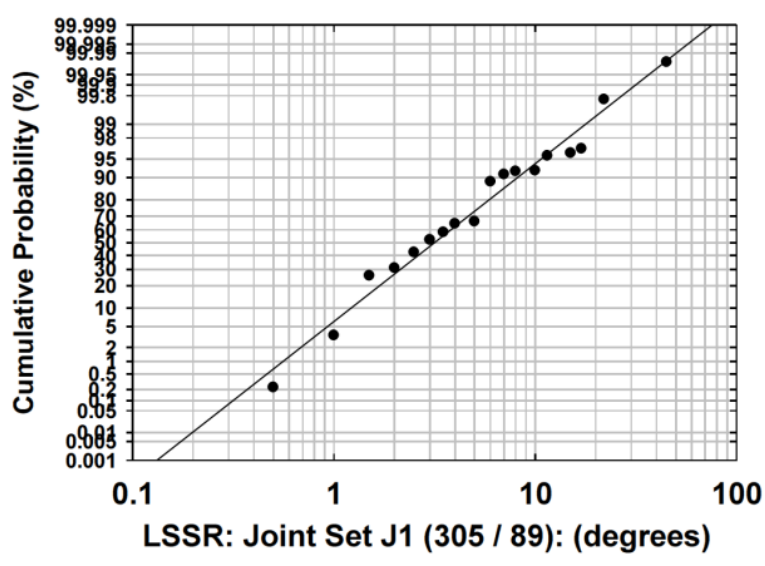

New South Wales Mine: Example 2004

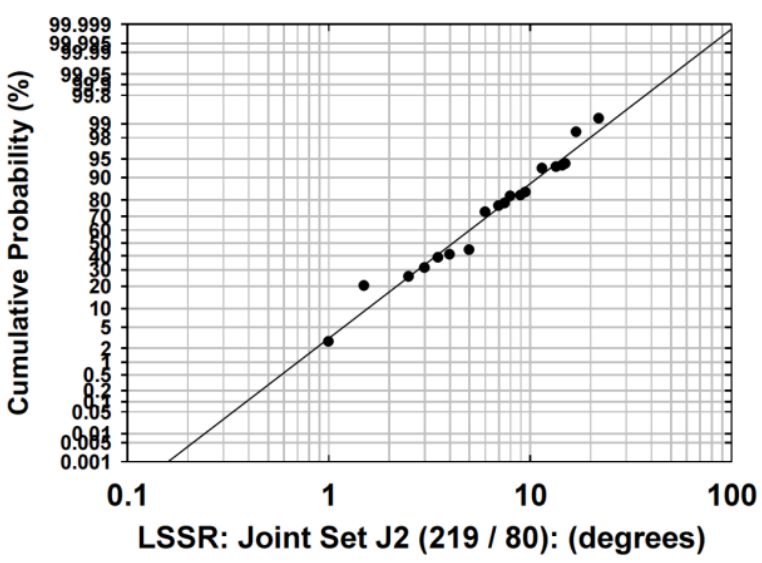

Figure 9 Examples of lognormally-distributed large-scale surface roughness (degrees)

\section{$9 \quad$ Defect spacing}

Spacing is defined as the distance between adjacent members of the same orientation set. True spacing is measured at right-angles to the defect surfaces. Apparent spacing is the distance between adjacent defects of the same set, as may have been mapped along a line traverse along a slope face. As shown in the example presented as Figure 10, true spacing has a lognormal (base 10) distribution.
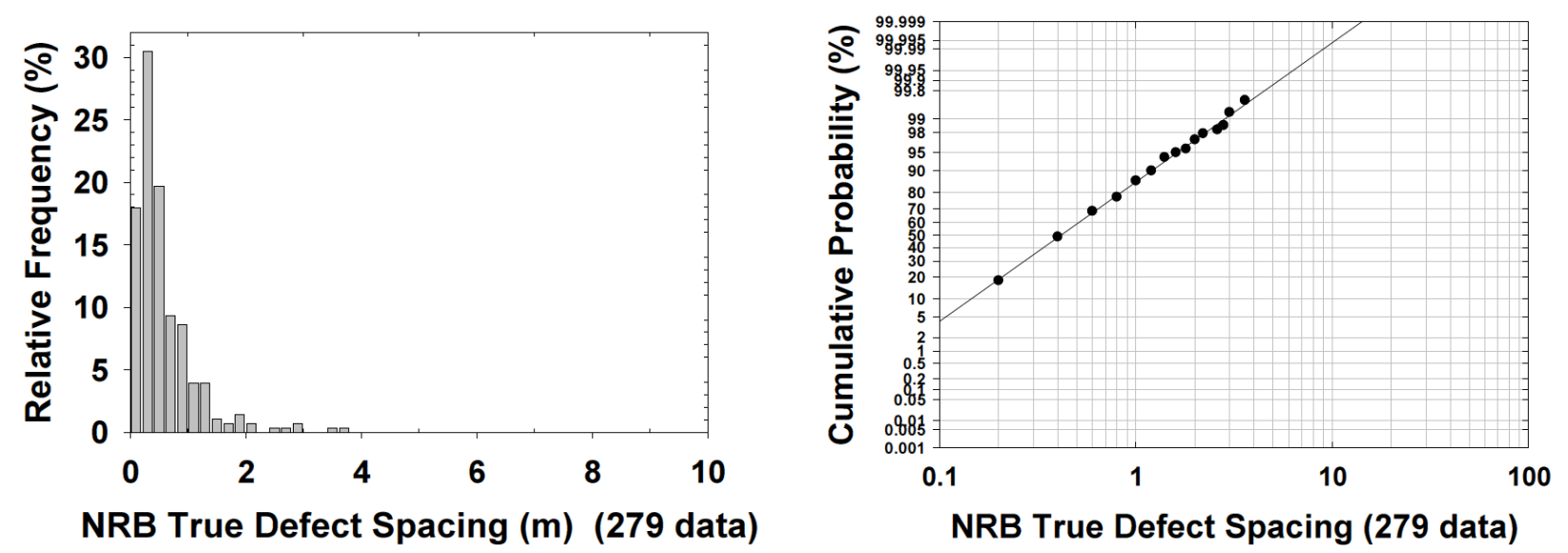

Figure 10 Example of lognormally-distributed spacing between defects of the same orientation set 


\section{Bridges between defects}

As shown earlier in Figure 2, for those geological defects not cut-off by other defects, there is either an intact rock or rock mass bridge between adjacent defects.

The statistical distribution of intact rock bridge lengths is lognormal (base 10), as shown in the example presented as Figure 11.

New South Wales Mine: Example 2004

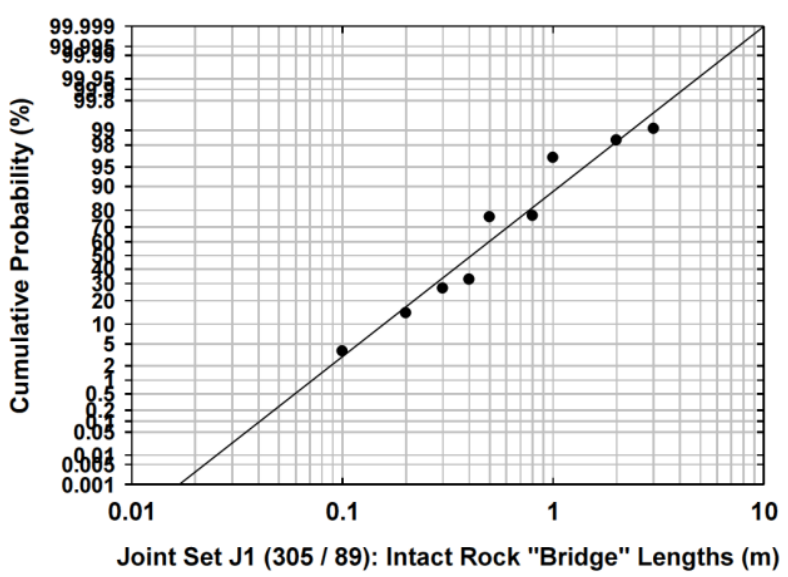

Queensland Mine: Example 2006

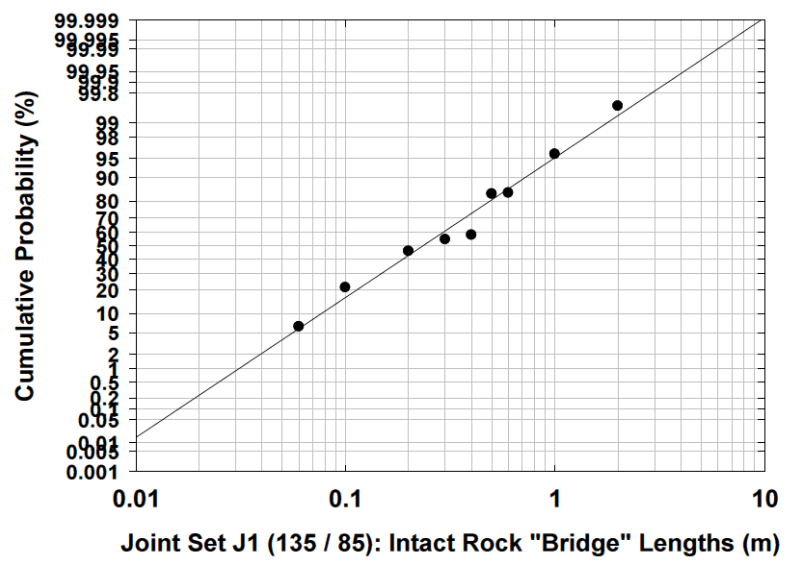

Figure 11 Example of lognormally-distributed intact rock bridge lengths between non cut-off defects

\section{Hoek-Brown, defect and Step-Path shear strength models}

A suite of Hoek-Brown, defect and Step-Path shear strength models were developed.

$A m_{i}$ value of 8 and $D$ value of 0 were adopted throughout.

The Hoek-Brown method was used to compute via ROCLAB software the intact rock shear strength model for UCS inputs ranging from 1 to $100 \mathrm{MPa}$ and GSI index from 81 to 89 (as appropriate for the UCS value being considered). Normal stress ranged from 0 to $10 \mathrm{MPa}$.

Likewise, the Hoek-Brown method was used to derive the rock mass shear strength model for the same range of UCS and normal stress values; but with the GSI index fixed at 50.

Barton's approach was used for developing the defect shear strength model. Inputs were Barton's small scale surface roughness of 3.6, large-scale undulation roughness of five degrees and same range of UCS values for joint wall-rocks and normal stress conditions as indicated above.

The Step-Path model comprised the following inputs:

- Defect length - fixed as either $4.2 \mathrm{~m}$ (actual length) or $2.4 \mathrm{~m}$ (apparent length).

- Probability of defect occurrence - variable ranging between 0 and $100 \%$.

- Probability of defect cut-off - variable ranging between 0 and $100 \%$.

- Bridge length - fixed as $0.4 \mathrm{~m}$.

- Bridge strength type - nominated as either intact rock or rock mass.

- Segments of Step-Path failure surface without defects - rock mass strength.

With the bridge length fixed at $0.4 \mathrm{~m}$, the ratios of bridge length to defect length considered in the present analysis were approximately $1 / 10$ and $1 / 6$ for the 4.2 and $2.4 \mathrm{~m}$ long defects, respectively. 


\section{Discussion of results}

What strength outcomes might be expected by varying the input parameters to the Step-Path analysis?

What are the conceptual implications of Figure 12 for the Step-Path strength model? There are three axes:

- A: Ratio (0 to 1 ) of defect length to bridge length.

- B: Probability of defect occurrence, expressed as a ratio 0 to 1.

- C: Probability of defect cut-off, again expressed as a ratio 0 to 1.

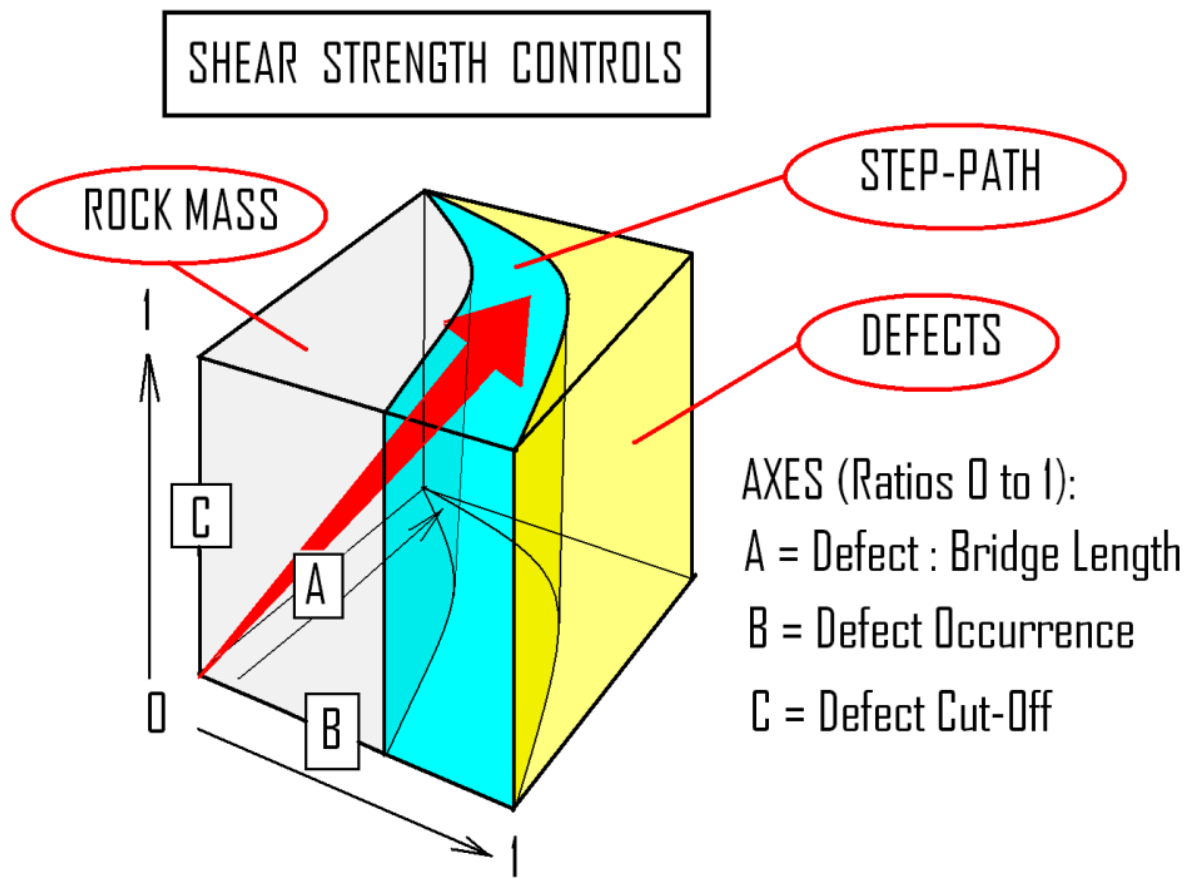

Figure 12 Factors expected to impact failure path shear strength

Firstly, Figure 12 is intended to show that a defect-controlled Step-Path strength model is not necessarily applicable to every portion of every rock mass.

Secondly, whilst only schematic and approximate, Axis B attempts to reinforce the principle that a Step-Path approach is only applicable along those segments of a failure path through a rock mass where a set of defect planes and failure path are broadly co-aligned.

Thirdly, notwithstanding the first two implications, Figure 12 shows that rock mass rather than Step-Path strength will dominate if:

- Axis A: bridges comprise rock mass materials and cumulative bridge length is much greater than the cumulative defect length.

- Axis B: critically orientated defects have low likelihood of occurrence in the rock mass (i.e. defects only occur in widely isolated pockets/zones).

- Axis C: most of the critically orientated defects are not cut-off (i.e. there are very many bridges between defects).

Fourthly, and to iterate conversely the third group of implications, the Step-Path model is most appropriate for rock mass situations where critically orientated defects (i.e. those co-aligned with the failure path) occur throughout the rock mass, where many of these defects are cut-off by other defects (i.e. there are very few bridges) and where the cumulative length of those few bridges that do occur is short relative to the cumulative length of the critically orientated defects. 
Analysis results for an intact rock UCS of $30 \mathrm{MPa}$ are summarised in Tables 3 to 5 and Figures 13 to 16 .

Table 3 Step-Path strength decrease relative to Hoek-Brown rock mass strength (defects $=2.4 \mathrm{~m}$ )

Strength decrease (\%) relative to Hoek-Brown rock mass shear strength at $1 \mathrm{MPa}$ normal stress

\begin{tabular}{|c|c|c|c|c|c|c|c|c|c|c|}
\hline \multirow{3}{*}{$\begin{array}{c}\text { Probability of } \\
\text { defect cut-off (\%) }\end{array}$} & \multicolumn{5}{|c|}{ Intact rock bridges (each $0.4 \mathrm{~m}$ long) } & \multicolumn{5}{|c|}{ Rock mass bridges (each $0.4 \mathrm{~m}$ long) } \\
\hline & \multicolumn{10}{|c|}{ Probability of defect occurrence (\%) (each defect $2.4 \mathrm{~m}$ long) } \\
\hline & 0 & 25 & 50 & 75 & 100 & 0 & 25 & 50 & 75 & 100 \\
\hline 100 & 0.00 & 10.48 & 20.96 & 31.44 & 41.92 & 0.00 & 10.48 & 20.96 & 31.44 & 41.92 \\
\hline 75 & 0.00 & 8.81 & 17.69 & 26.50 & 35.38 & 0.00 & 10.08 & 20.23 & 30.31 & 40.39 \\
\hline 50 & 0.00 & 7.21 & 14.42 & 21.63 & 28.84 & 0.00 & 9.75 & 19.43 & 29.17 & 38.92 \\
\hline 25 & 0.00 & 5.61 & 11.15 & 16.76 & 22.30 & 0.00 & 9.35 & 18.69 & 28.04 & 37.38 \\
\hline 0 & 0.00 & 3.94 & 7.88 & 11.88 & 15.82 & 0.00 & 8.95 & 17.96 & 26.90 & 35.91 \\
\hline
\end{tabular}

Table 4 Step-Path strength decrease relative to Hoek-Brown rock mass strength (defects $=4.2 \mathrm{~m}$ )

\begin{tabular}{ccccccccccccc}
\hline \multicolumn{3}{c}{ Strength decrease (\%) relative to Hoek-Brown rock mass shear strength at $\mathbf{1}$ MPa normal stress } \\
\hline $\begin{array}{c}\text { Probability of } \\
\text { defect cut-off (\%) }\end{array}$ & \multicolumn{8}{c}{ Intact rock bridges (each $\mathbf{0 . 4} \mathbf{m}$ long) } & \multicolumn{5}{c}{ Rock mass bridges (each $\mathbf{0 . 4} \mathbf{m}$ long) } \\
\cline { 2 - 13 } & $\mathbf{0}$ & $\mathbf{2 5}$ & $\mathbf{5 0}$ & $\mathbf{7 5}$ & $\mathbf{1 0 0}$ & $\mathbf{0}$ & $\mathbf{2 5}$ & $\mathbf{5 0}$ & $\mathbf{7 5}$ & $\mathbf{1 0 0}$ \\
\hline $\mathbf{1 0 0}$ & 0.00 & 10.48 & 20.96 & 31.44 & 41.92 & 0.00 & 10.48 & 20.96 & 31.44 & 41.92 \\
$\mathbf{7 5}$ & 0.00 & 9.48 & 18.96 & 28.44 & 37.91 & 0.00 & 10.21 & 20.49 & 30.71 & 40.99 \\
$\mathbf{5 0}$ & 0.00 & 8.48 & 16.96 & 25.43 & 33.98 & 0.00 & 10.01 & 20.03 & 30.04 & 40.05 \\
$\mathbf{2 5}$ & 0.00 & 7.48 & 15.02 & 22.50 & 29.97 & 0.00 & 9.81 & 19.56 & 29.37 & 39.19 \\
$\mathbf{0}$ & 0.00 & 6.48 & 13.02 & 19.49 & 26.03 & 0.00 & 9.55 & 19.16 & 28.70 & 38.25 \\
\hline
\end{tabular}

Table 5 Step-Path strength increase relative to Hoek-Brown rock mass strength as mean defect length decreases from 4.2 to $2.4 \mathrm{~m}$

\begin{tabular}{|c|c|c|c|c|c|c|c|c|c|c|}
\hline \multirow{3}{*}{$\begin{array}{c}\text { Probability of } \\
\text { defect cut-off (\%) }\end{array}$} & \multicolumn{5}{|c|}{ Intact rock bridges (each $0.4 \mathrm{~m}$ long) } & \multicolumn{5}{|c|}{ Rock mass bridges (each $0.4 \mathrm{~m}$ long) } \\
\hline & \multicolumn{10}{|c|}{ Probability of defect occurrence (\%) } \\
\hline & 0 & 25 & 50 & 75 & 100 & 0 & 25 & 50 & 75 & 100 \\
\hline 100 & 0.00 & 0.00 & 0.00 & 0.00 & 0.00 & 0.00 & 0.00 & 0.00 & 0.00 & 0.00 \\
\hline 75 & 0.00 & 0.67 & 1.27 & 1.94 & 2.53 & 0.00 & 0.13 & 0.26 & 0.40 & 0.60 \\
\hline 50 & 0.00 & 1.27 & 2.54 & 3.80 & 5.14 & 0.00 & 0.26 & 0.60 & 0.87 & 1.13 \\
\hline 25 & 0.00 & 1.87 & 3.87 & 5.74 & 7.67 & 0.00 & 0.46 & 0.87 & 1.33 & 1.81 \\
\hline 0 & 0.00 & 2.54 & 5.14 & 7.61 & 10.21 & 0.00 & 0.60 & 1.20 & 1.80 & 2.34 \\
\hline
\end{tabular}



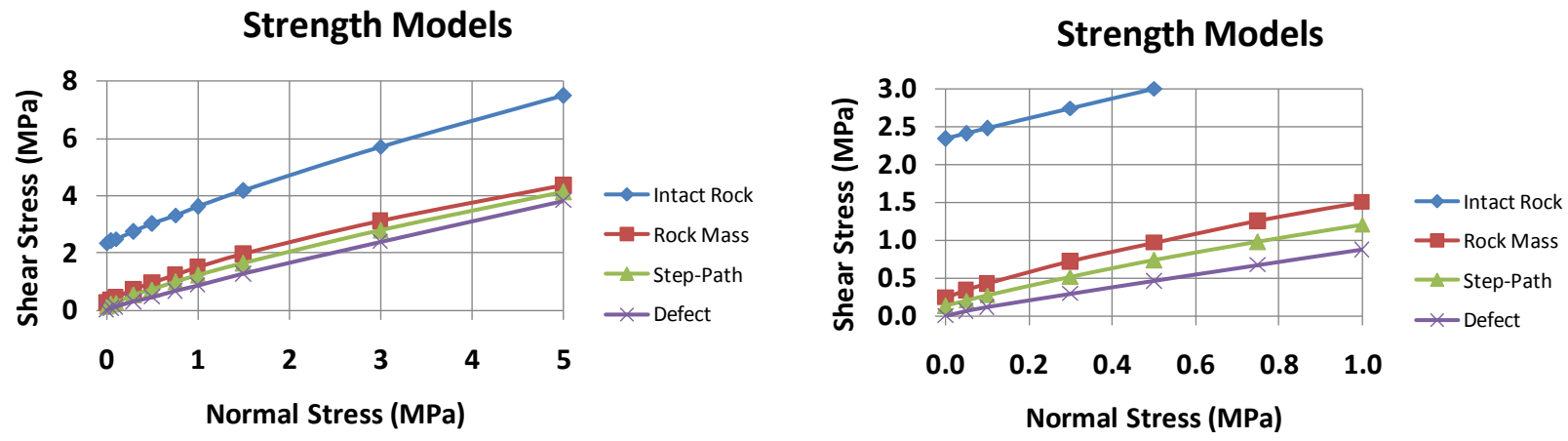

Figure 13 Shear strength models for intact rock UCS of $30 \mathrm{MPa}$

DEFECT 2.4m: IR BRIDGE 0.4m: SHEAR STRENGTH

DEFECT 2.4m: RM BRIDGE 0.4m: SHEAR STRENGTH

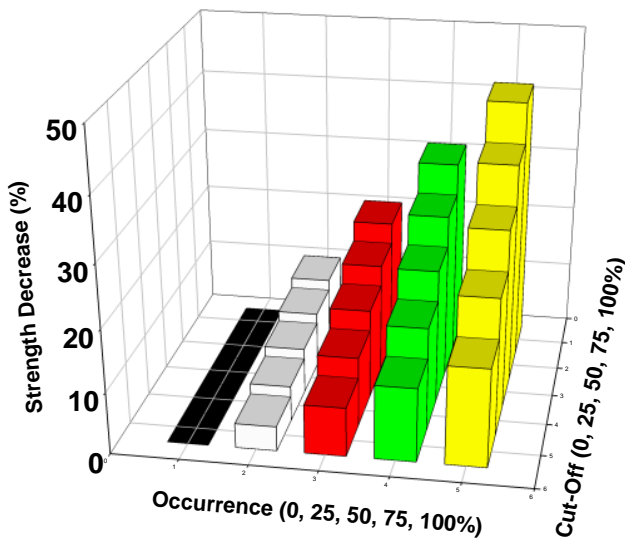

(a)

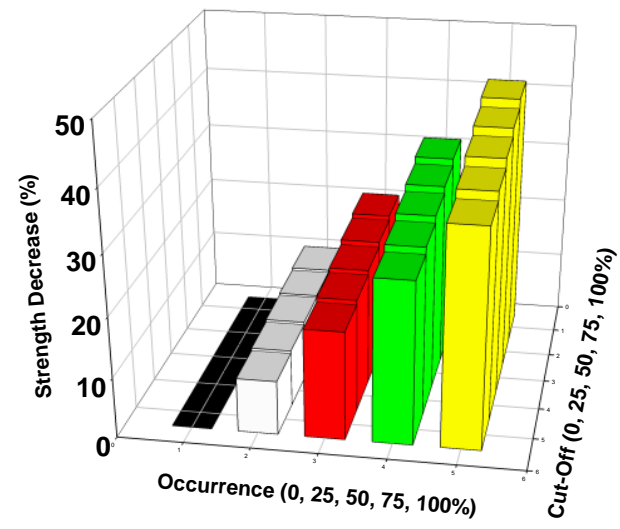

(b)

Figure 14 Step-Path strength decrease relative to Hoek-Brown rock mass strength (defects $=2.4 \mathrm{~m}$ ).

(a) Bridge type - intact rock; (b) Bridge type - rock mass

DEFECT 4.2m: IR BRIDGE 0.4m: SHEAR STRENGTH

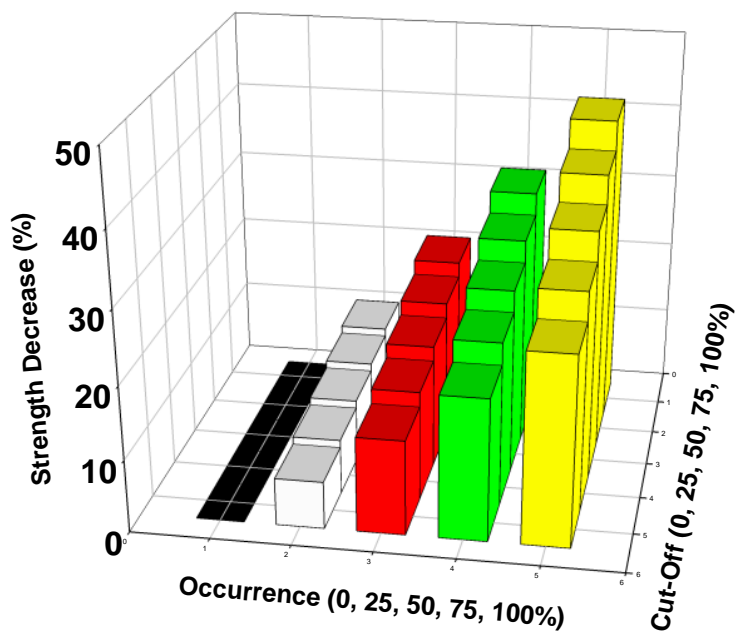

(a)
DEFECT 4.2m: RM BRIDGE 0.4m: SHEAR STRENGTH

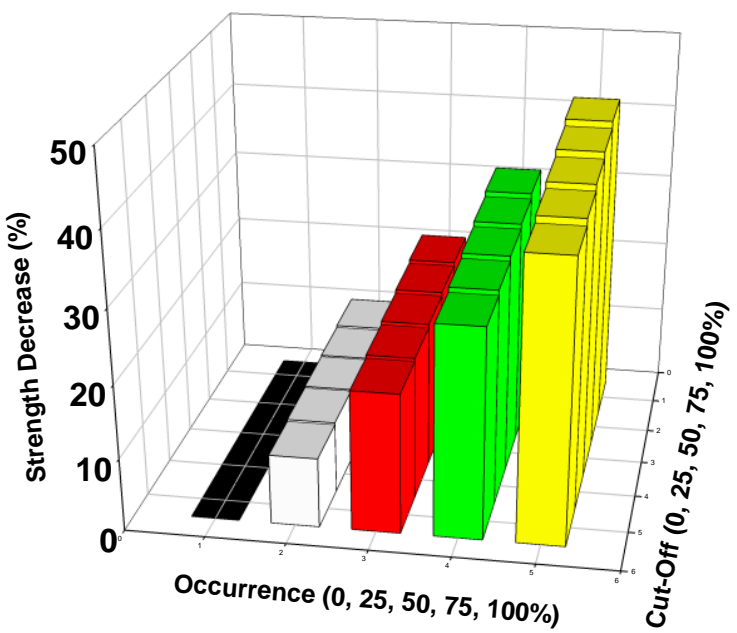

(b)

Figure 15 Step-Path strength decrease relative to Hoek-Brown rock mass strength (defects $=4.2 \mathrm{~m}$ ).

(a) Bridge type - intact rock; (b) Bridge type - rock mass 

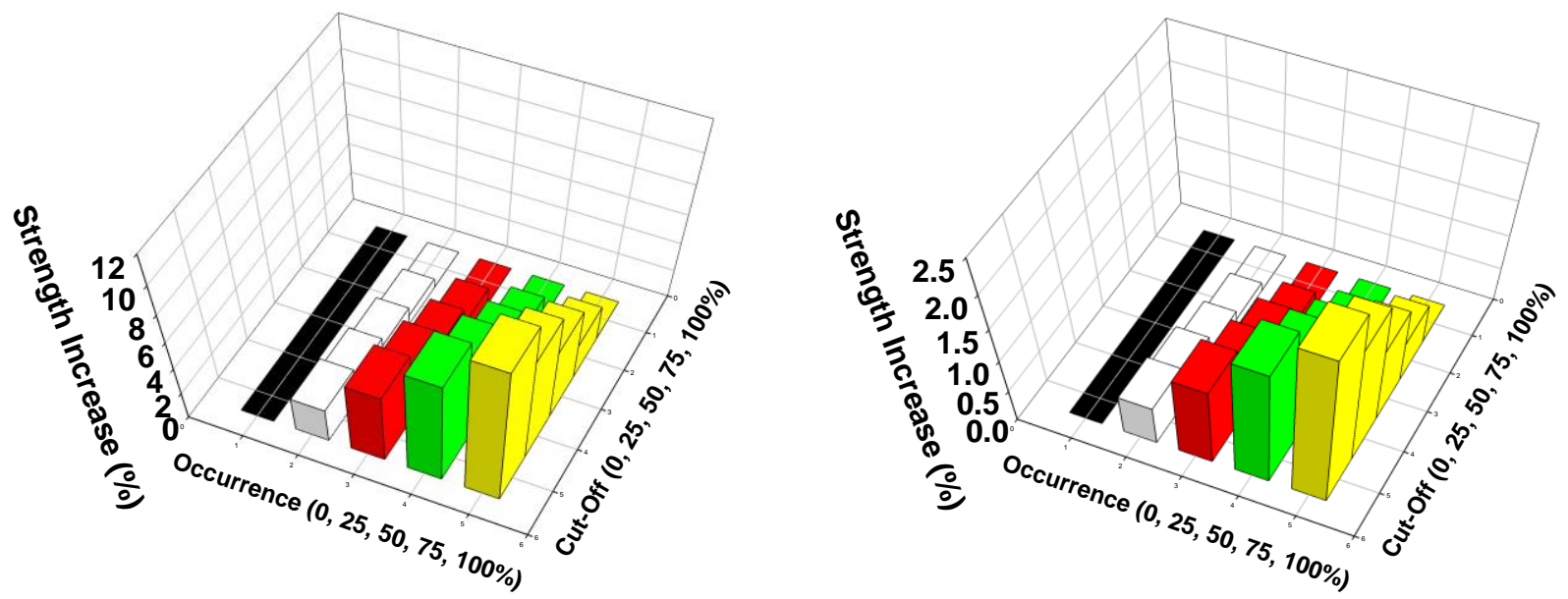

Figure 16 Step-Path strength increase (relative to Hoek-Brown rock mass strength) as mean defect length decreases from 4.2 to $2.4 \mathrm{~m}$

Figure 14 is a base case. It compares intact-rock, rock-mass, Step-Path (combination of rock mass, 50\% probability of defects and $50 \%$ probability of cut-off, i.e. bridges) and defect-only shear strength models.

As may be expected, the Step-Path strength curve is typically positioned between the Hoek-Brown rock mass and Barton's defect strength curves. The Step-Path curve cannot be less than the defect curve; as the latter corresponds to a situation where the failure path is entirely defined by defects without intact rock or rock mass bridges between any of the defects. However, the Step-Path curve could exceed the rock mass curve in situations where there is a sufficient cumulative length of intact rock (i.e. not rock mass) bridges between defects along the failure path.

Since the mean bridge length is kept constant at $0.4 \mathrm{~m}$, as the defect length is decreased from 4.2 to $2.4 \mathrm{~m}$, an increase in Step-Path strength is anticipated for the same relative proportion of $0.4 \mathrm{~m}$ long bridges.

For the purposes of results comparison, the base strength case is the Hoek-Brown rock mass strength.

For the first objective, the Step-Path (defects and bridges) results are expressed as percentage decrease along the failure path as compared to a failure path entirely comprising Hoek-Brown rock mass.

For the second objective, a somewhat similar presentation of results approach is used. The tabulated and plotted results indicate how much stronger the Step-Path failure path comprising $2.4 \mathrm{~m}$ long defects is than one comprising 4.2 m long defects; again expressed relative to Hoek-Brown rock mass strength.

The following Step-Path strength comments can be made:

- For purposes of comparison, all discussion is for shear strength results at $1 \mathrm{MPa}$ normal stress.

- Intact rock is approximately $240 \%$ stronger than rock mass.

- At $0 \%$ probability of defect occurrence and cut-off, Step-Path and Hoek-Brown results are the same.

- At $100 \%$ probability of defect occurrence and cut-off, Step-Path and Barton's defect strength are the same.

- For the specific Hoek-Brown and Barton parameter inputs adopted in this paper, defects-only shear strength is $42 \%$ less than the Hoek-Brown rock mass only strength.

- The defect length to bridge length ratio is 4.2 to 0.4 for the actual defect length model (circular shape planes). 
- The defect length to bridge length ratio is 2.4 to 0.4 for the apparent defect length model (circular shape planes).

- For intact rock bridges between actual $4.2 \mathrm{~m}$ long defects, Step-Path strength decreases by $6.5 \%$ for each $25 \%$ increment in probability of defect occurrence (at $0 \%$ probability of defect cut-off, i.e. there is an intact rock bridge between every defect).

- For intact rock bridges between apparent $2.4 \mathrm{~m}$ long defects, Step-Path strength decreases by $3.9 \%$ for each $25 \%$ increment in probability of defect occurrence (at $0 \%$ probability of defect cut-off, i.e. there is an intact rock bridge between every defect).

- For rock mass bridges between actual $4.2 \mathrm{~m}$ long defects, Step-Path strength decreases by $9.5 \%$ for each $25 \%$ increment in probability of defect occurrence (at $0 \%$ probability of defect cut-off, i.e. there is a rock mass bridge between every defect).

- For rock mass bridges between apparent $2.4 \mathrm{~m}$ long defects, Step-Path strength decreases by about $9.0 \%$ for each $25 \%$ increment in probability of defect occurrence (at $0 \%$ probability of defect cut-off, i.e. there is a rock mass bridge between every defect).

- There are similar but lower magnitude trends in Step-Path strength decrease for each $25 \%$ increment in probability of defect cut-off.

- The error in defect length estimation (actual versus apparent) has a maximum $10 \%$ shear strength impact when there are intact rock bridges between all defects along the Step-Path. This impact decreases to $2.5 \%$ for rock mass bridges.

\section{Conclusion}

Geological defect and bridge attributes for statistical models input to the Step-Path method should be determined by line traverse mapping of slope faces; not by window/area or volume mapping.

Mapped geological defect and bridge attributes appear to be lognormally distributed. The only exception is perhaps small-scale surface roughness.

Various factors impact the geological defect length model. For circular-shaped defect surfaces, apparent lengths measured in slope faces may be $60 \%$ less than actual lengths. For elliptical or rectangular shape defects, mapping in the direction perpendicular to the short axis of the defect shape may underestimate the long-axis length by 60 to $80 \%$. Where rock masses comprise several defect sets, defect cut-off by other defects is common. With increasing proportion of cut-off defects, shapes of defect planes become more complex and irregular, and on average, actual and apparent lengths are likely very similar.

The Hoek-Brown strength calculation yields the same answer irrespective of defect orientation and length.

Factors impacting the Hoek-Brown method are inputs for UCS, GSI, mi and D. These Hoek-Brown factors also apply to those parts of Step-Path traverse that are not co-aligned with geological defects or comprise rock mass bridges between defects.

Factors impacting the Step-Path method are defect orientation, defect length relative to bridge length, probability of defect occurrence, probability of defect cut-off and strength of bridges between non cut-off defects (i.e. whether intact rock or rock mass). Depending on defect pattern and likely slope failure mode, Step-Path method may sometimes apply to only parts of the overall failure path through the rock slope.

The strength difference between Hoek-Brown and Step-Path failure paths will depend on input parameters to both methods. For parameters used in this paper, the strength of a Step-Path fully defined by defects is about $40 \%$ less than the Hoek-Brown rock mass strength.

At $50 \%$ probability for both, defect occurrence and cut-off, the strength of Step-Path traverse is about 15 to $20 \%$ less than the corresponding Hoek-Brown strength, irrespective of bridge type. Since many mine 
slopes are designed to Factors of Safety of about 1.25 to 1.35 , a 15 to $20 \%$ reduction in shear strength would result in actual Factors of Safety being close to 1.

For $75 \%$ probability for both defect occurrence and cut-off the Step-Path strength is about 25 to $30 \%$ less than the Hoek-Brown strength estimate. At these strength reductions, a purely Hoek-Brown designed slope will have Factors of Safety less than one if re-assessed by the Step-Path method for the entire length of the failure path through the slope.

Shear strength impact caused by underestimating defect length is less severe than initially expected. For the presented example, the maximum strength difference is between 3 and $12 \%$ (depending on bridge type). But, there would have been a greater difference if a weaker defect model had been used.

\section{Acknowledgement}

The late Dr Barry McMahon championed the Step-Path approach, developed the original STEPSIM software for rock slope design and sparked the writer's interest.

\section{References}

Baczynski, NRP 1980, 'Rock mass characterization and its application to assessment of unsupported underground openings', PhD thesis, dated Nov 1980, Department of Mining \& Metallurgy, University of Melbourne, Australia, p. 233.

Baczynski, NRP 2000, 'STEPSIM4 Step-Path method for slope risks', in Proceedings for GeoEng 2000: International Conference on Geotechnical and Geological Engineering, Melbourne, vol. 2, p. 86.

Barton, N 1976, 'The shear strength of rock and rock joints', International Journal of Rock Mechanics and Mining Sciences \& Geomechanics Abstracts, vol. 13, pp. 1-24.

Bieniawski, ZT 1989, Engineering Rock Mass Classifications, John Wiley \& Sons, p. 251.

Carvalho, JL, Carter, TG \& Diederichs, MS 2007, 'An approach for prediction of strength and post yield behaviour for rock masses of low intact strength', in Rock Mechanics: Meeting Society's Challenges and Demands, pp. 249-257.

Hoek, E \& Brown, ET 1980a, 'Empirical strength criterion for rock masses', Journal of the Geotechnical Engineering Division, ASCE, vol. 106, no. GT9, pp. 1013-1035.

Hoek, E \& Brown, ET 1980b, Underground Excavations in Rock, London Institution of Mining and Metallurgy.

Jennings, JE 1970, 'A mathematical theory for the calculation of the stability of slopes in opencast mines', in Proceedings of Symposium on the Theoretical Background to the Planning of Open Pit Mines, Johannesburg, pp. 87-102.

Little, LN, Cortes, JP \& Baczynski, NR 1999, Risk-based slope design optimisation study for the Ok Tedi copper-gold mine: Volume 5: Geotechnical models and failure modes, internal report dated 30 Aug 1999, Ok Tedi Mining Limited, Mine Technical Services Department, Geotechnical Engineering Section, p. 108 \& Appendices A to F.

McMahon, BK 1971, 'Statistical methods for the design of rock slopes', in Proceedings of the First Australia-New Zealand Conference on Geomechanics', vol. 1, pp. 314-321.

McMahon, BK 1974, 'Design of rock slopes against sliding on pre-existing fractures', in Proceedings of the 3rd Congress of the International Society for Rock Mechanics, National Academy of Sciences, Washington DC, vol. IIB, pp. 803-808.

McMahon, BK 1979, 'Report to Bougainville Copper Limited on slope design studies, Pan Hill', McMahon Burgess \& Yates, Sydney, internal report.

Read, JRL \& Lye, GN 1983, 'Pit slope design methods, Bougainville Copper Limited open cut', in Proceedings of the 5th Congress of the International Society for Rock Mechanics, Rotterdam, Balkema, Melbourne, vol. 1, pp. C93-C98. 
